\title{
Small hiatal hernia as a risk factor of atrial fibrillation
}

\author{
Jan Głowacki ${ }^{12 A, C D}$, Szymon Florek ${ }^{3 B, E, F}$, Alexander Suchodolski ${ }^{3 B, E, F}$, Jarosław Wasilewski ${ }^{A A, C D}$ \\ 'Department of Radiology and Radiodiagnostics, Silesian Medical University, Zabrze, Poland \\ ${ }^{2}$ Silesian Centre for Heart Diseases, Zabrze, Poland \\ ${ }^{3}$ Student Research Group, Medical University of Silesia in Katowice, School of Medicine with the Division of Dentistry in Zabrze, Zabrze, Poland \\ ${ }^{4} 3^{\text {rd }}$ Department of Cardiology, Faculty of Medical Sciences in Zabrze, Medical University of Silesia, Katowice, Poland
}

\section{Abstract}

Purpose: Hiatal hernia $(\mathrm{HH})$ is considered a risk factor of atrial fibrillation (AF). The aim of this study was to evaluate $\mathrm{HH}$ in computed tomography (CT) images in patients awaiting ablation due to atrial fibrillation, and to look for a correlation between $\mathrm{HH}$ in patients without $\mathrm{AF}$ and with $\mathrm{AF}$.

Material and methods: This study included 441 patients divided in two groups: 207 patients subjected to computed tomography before ablation procedure due to atrial fibrillation and 234 patients as the control group, who underwent $\mathrm{CT}$ scans to rule out coronary disease (no AF in history).

Results: Small HH, e.g. under or equal to $2 \mathrm{~cm}$, are associated with a higher risk of AF compared to the control group, which was not observed for bigger $\mathrm{HH}$.

Conclusions: The presence of small $\mathrm{HH}$ may be a risk factor of AF.

Key words: hiatal hernia, atrial fibrillation, computed tomography.

\section{Introduction}

Atrial fibrillation (AF) is one of the most common arrhythmias. The prevalence in patients $\geq 65$ years old is $4.8 \%$ in women and $6.2 \%$ in men [1]. The most important risk factors are as follows: age $>60$ years, arterial hypertension, and heart diseases (coronary artery disease, cardiomyopathy, pericardial inflammation, prior heart attacks, congestive heart failure, etc.). According to the RecordAF study, $15.6 \%$ of patients with recently diagnosed AF in Poland have AF without any underlying heart disease [2]. In this considerable group of patients, we tried to look for other possible causes. There is an increasing amount of literature on the influence of hiatal hernia $(\mathrm{HH})$ with occurrence of AF. HH is defined as the protrusion of intra-abdominal structures through a dilated oesophageal hiatus. In the USA $60 \%$ of patients over 50 years old have $\mathrm{HH}$ [3]. Cases of AF in which a surgical repair of $\mathrm{HH}$ treated the arrhythmia seem to confirm a cause and effect relation of this two diseases [4]. Most studies concentrate on how many patients with $\mathrm{HH}$ also have AF. Roy et al. reported that $5.3 \%$ of patients with $\mathrm{HH}$ had also AF.

The aim of this paper is to investigate how many patients with AF waiting for an ablation have $\mathrm{HH}$. We think such results are interesting for clinicians, because this lesion, as an increasing number of studies suggest, may be another risk factor for AF. Moreover, the mentioned case reports show that it may be a treatable cause. Radiologists should be aware of the role that $\mathrm{HH}$ may play in the pathomechanism of AF, so it should be reported in every patient with AF.

The multi-detector row computed tomography (MDCT) can visualise anatomical structures with high resolution. In cardiology, MDCT can be used to determine the coronary calcium score, the coronary arteries (coronary CT angiography - CCTA). Furthermore, CCTA is used to visualise

\section{Correspondence address:}

Alexander Suchodolski, MD, Silesian Centre for Heart Diseases, Marii Skłodowskiej-Curie 9, 41-800 Zabrze, Poland, phone: +48323733600 ,

e-mail: alex.suchodolski@gmail.com

Authors' contribution:

A Study design · B Data collection · C Statistical analysis · D Data interpretation · E Manuscript preparation · F Literature search · G Funds collection 

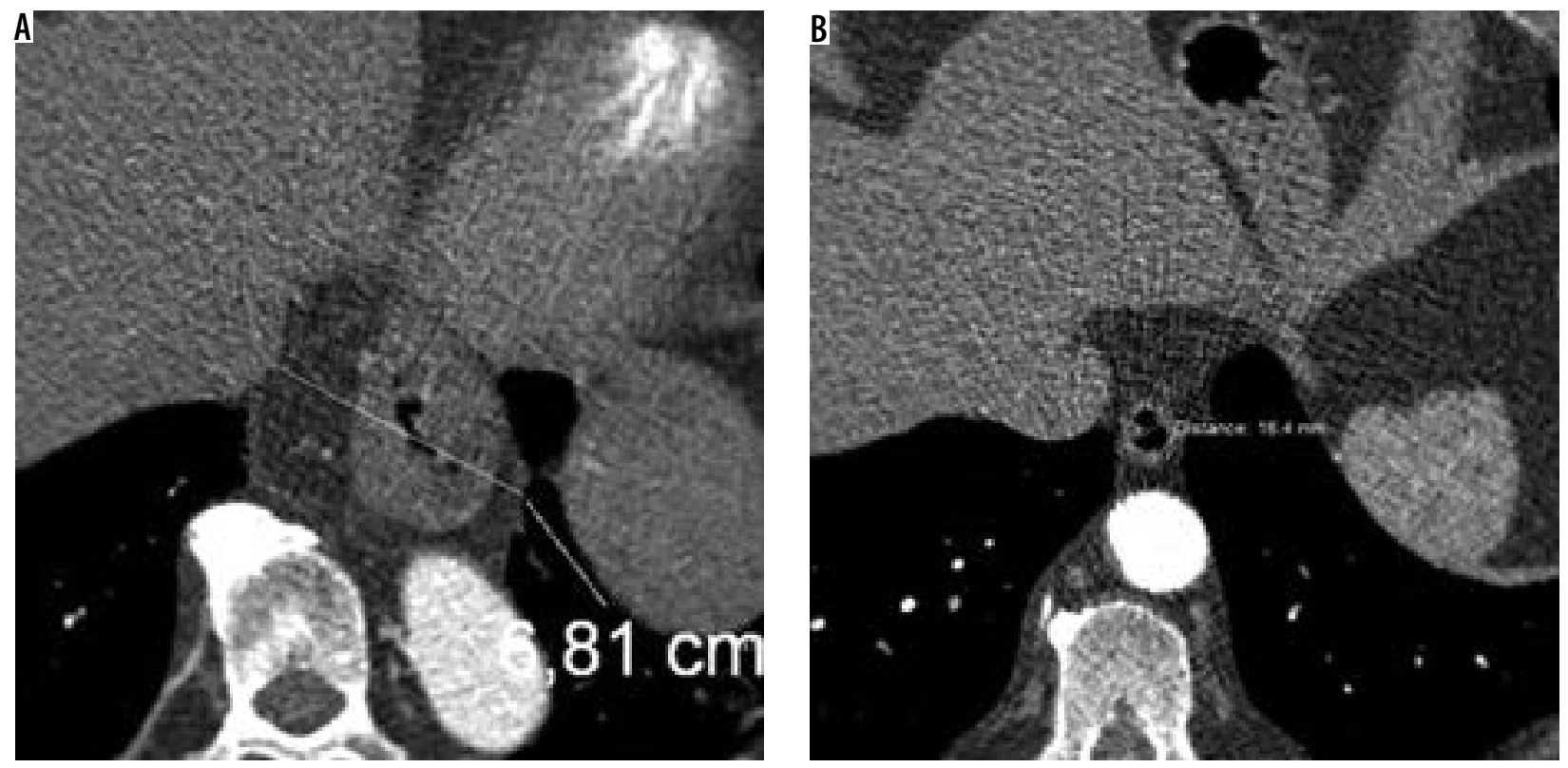

Figure 1. Computed tomography images of one of the biggest (A) and one of the smallest (B) hiatal hernias in our study population

coronary atherosclerosis, coronary stents, bypass grafts, coronary and pulmonary veins, and general morphology of the heart and vessels [5]. The clinical applications of cardiac CT involve AF wherein it is used for visualisation of the anatomy of pulmonary veins necessary for atrial ablation - treatment of AF.

\section{Material and methods}

The study included 207 patients with planned ablation of pulmonary veins and 234 in the control group, which consisted of patients who had CT examination (CCTA) to exclude coronary disease. No scans were performed only for the purpose of this study, all the patients were sent for CT due to medical reasons, and the study was retrospective. The control group consisted of 71 women and 163 men (mean age $59.01 \pm 10.57$ years, range $24-83$ years), and the study group included 78 women and 129 men (mean age $58.07 \pm 11.55$ years, range $21-87$ years). The inclusion criterion was diagnosed AF; whereas, there was no AF in the control group. The study included 442 CT chest examinations on a dual-source CT scanner (SOMATOM Definition Flash, Siemens Heathineers, Forchheim, Germany) in the Silesian Centre for Heart Disease in Zabrze, Poland. Hiatal hernias were observed and measured in each CT examination (Figure 1). The radiologists detected all hiatal hernias in CT scans without dividing into slide or paraesophageal $\mathrm{HH}$. In the AF group no patients had symptoms of gastro-oesophageal reflux disease (GERD).

The statistical analysis was carried out with the Statistica 10 package (StatSoft, United States), with the threshold of statistical significance set at $p \leq 0.05$. The $\chi^{2}$ test and some variations of this $\left(\chi^{2}\right.$ with Yates corrected and Fisher exact) were performed.

\section{Results}

We analysed the data of 207 patients in the study group and 234 in the control group. Baseline characteristics are summarised in Table 1 . In the study group 10 patients (4.83\%) had an $\mathrm{HH}$ of $2 \mathrm{~cm}$ or less and 19 (9.18\%) had $\mathrm{HH}$ greater than $2 \mathrm{~cm}$; whereas, in the control group these were $2(0.85 \%)$ and $26(11.11 \%)$, respectively. The statistical analysis shows that the prevalence of small $\mathrm{HH}(\leq 2 \mathrm{~cm})$ is almost 6 times higher in the study group compared to the control group, which is not observed for large $\mathrm{HH}$. This parameter is statistically significant in the analysis with the Yates $\chi^{2}$ test $(p=0.026)$, but it has weak association, with a contingency coefficient of 0.13 . No more correlations were found in statistical analysis.

\section{Discussion}

The largest study up till now that focused on this issue showed that $7.1 \%$ of patients with $\mathrm{HH}$ also had AF, compared to $1 \%$ of the general population [6]. There was no breakdown of patients with $\mathrm{HH}$ into type or size groups [6]. Our research demonstrated that $\mathrm{HH}$ with a size smaller than $2 \mathrm{~cm}$ is correlated with a higher risk of atrial fibrillation. We could not prove correlation between large $\mathrm{HH}$ and AF. The explanation may be that our control group consisted of patients enrolled for CCTA because of clinical symptoms such as heartburn. This could have resulted in a larger number of $\mathrm{HH}$ in our control group than in the general population. The most common theory of how $\mathrm{HH}$ can trigger AF is mechanical irritation of the left atrium. There are cases of AF treatment due to $\mathrm{HH}$ repair, but the sizes of these lesions are substantially larger, for example two-thirds of the stomach above the diaphragm in a case reported by Cristian et al. [4]. 
Table 1. The analysis of our data in relation to age, sex, and diameter of $\mathrm{HH}$

\begin{tabular}{|c|c|c|c|c|c|c|c|}
\hline Parameter & $\begin{array}{c}\text { Study } \\
\text { group, } \\
n\end{array}$ & $\begin{array}{c}\text { Percentage } \\
\text { of study group } \\
(\%)\end{array}$ & $\begin{array}{l}\text { Control } \\
\text { group, } \\
n\end{array}$ & $\begin{array}{c}\text { Percentage of } \\
\text { control group } \\
(\%)\end{array}$ & $\begin{array}{c}\text { Total (study and } \\
\text { control groups), } \\
n\end{array}$ & $\begin{array}{l}\text { Percentage } \\
\text { of total } \\
(\%)\end{array}$ & $p$-value \\
\hline Number in total & 207 & 100 & 234 & 100 & 441 & 100 & - \\
\hline \multicolumn{8}{|l|}{ Age (years) } \\
\hline$<55$ & 67 & 32.37 & 70 & 29.91 & 137 & 31.07 & - \\
\hline$\geq 55$ & 140 & 62.63 & 164 & 70.09 & 304 & 68.93 & - \\
\hline \multicolumn{8}{|l|}{ Sex } \\
\hline Male & 129 & 62.32 & 71 & 30.34 & 200 & 45.35 & - \\
\hline Female & 78 & 37.68 & 163 & 69.66 & 241 & 54.65 & - \\
\hline \multicolumn{8}{|l|}{$\mathrm{HH}$} \\
\hline$\leq 2 \mathrm{~cm}$ & 10 & 4.83 & 2 & 0.85 & 12 & 2.72 & 0.026 \\
\hline$>2 \mathrm{~cm}$ & 19 & 9.18 & 26 & 11.11 & 45 & 10.20 & 0.71 \\
\hline Total & 29 & 14.01 & 28 & 11.97 & 57 & 12.93 & 0.62 \\
\hline
\end{tabular}

Naoum et al. showed in a study with 52 patients with large $\mathrm{HHs}$, defined as a hernia consisting of $\geq 30 \%$ intrathoracic stomach, that they can cause haemodynamic changes and dyspnoea [7]. While radiologists are describing CT scans of the heart, they should measure diameters of $\mathrm{HH}$, to rule out one possible and treatable mechanism causing AF. Our study may suggest that there are different possible ways to correlate atrial fibrillation and hiatus hernias. Perhaps, mechanical irritation is only one of many causes.

\section{Conclusions}

In our statistical analysis $\mathrm{HH}$ less than or equal to $2 \mathrm{~cm}$ is a risk factor of $\mathrm{AF}$, which was not observed for large $\mathrm{HH}$.

\section{Conflict of interest}

The authors report no conflict of interest.

\section{References}

1. Furberg C, Psaty B, Manolio T, et al. Prevalence of atrial fibrillation in elderly subjects (the Cardiovascular Health Study). Am J Cardiol 1994; 74: 236-241.

2. Opolski G, Kosior D, Kurzelewski M, et al. Baseline characteristics of patients from Poland enrolled in the global registry of patients with recently diagnosed atrial fibrillation (RecordAF). Kardiol Pol 2010; 68: 546-554.

3. Armaganijan L, Patel D, Lopes R, et al. Gastroesophageal reflux and atrial fibrillation: is there any correlation? Expert Rev Cardiovasc Ther 2012; 10: 317-322.

4. Cristian D, Constantin A, Barbu M, et al. Paroxysmal postprandial atrial fibrilation suppressed by laparoscopic repair of a giant paraesophageal hernia compressing the left atrium. J Gastrointestin Liver Dis 2015; 24: 113-116.
5. Schroeder S, Achenbach S, Bengel F, et al. Cardiac computed tomography: indications, applications, limitations, and training requirements: Report of a Writing Group deployed by the Working Group Nuclear Cardiology and Cardiac CT of the European Society of Cardiology and the European Council of Nuclear Cardiology. Eur Heart J 2008; 29: 531-556.

6. Roy R, Sagar S, Bunch T, et al. Hiatal hernia is associated with an increased prevalence of atrial fibrillation in young patients. J Atr Fibrillation 2013; 6: 894.

7. Naoum C, Falk G, Ng A, et al. Left atrial compression and the mechanism of exercise impairment in patients with a large hiatal hernia. J Am Coll Cardiol 2011; 58: 1624-1634. 